$11-1-2020$

\title{
Increasing use of antenatal care services among women in Kebbi State
}

Breakthrough RESEARCH

Follow this and additional works at: https://knowledgecommons.popcouncil.org/departments_sbsr-rh How does access to this work benefit you? Let us know!

\section{Recommended Citation}

Breakthrough RESEARCH. 2020. "Increasing use of antenatal care services among women in Kebbi State," infographic. Washington, DC: Population Council. 


\section{Increasing Use of Antenatal Care Services Among Women in Kebbi State}

The Breakthrough RESEARCH project conducted a behavioral surveillance survey for health among women who had a pregnancy or birth in the previous two years.

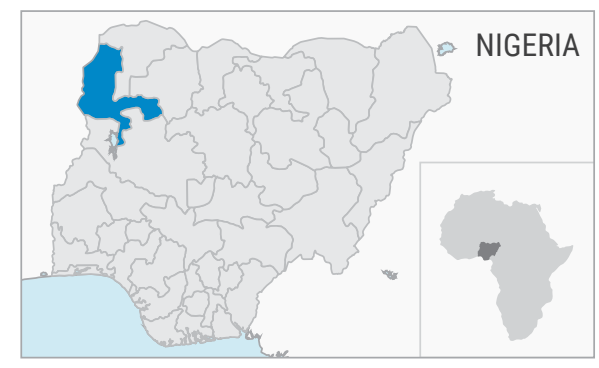

\section{Survey Findings for Kebbi State}

The behavioral surveillance survey identified three important factors for improving women's attendance of antenatal care four or more times (ANC4+) during pregnancy. The percentage in each box below is the median (50th percentile). Half of local government authorities (LGAs) are below (red) and half above this value (green).
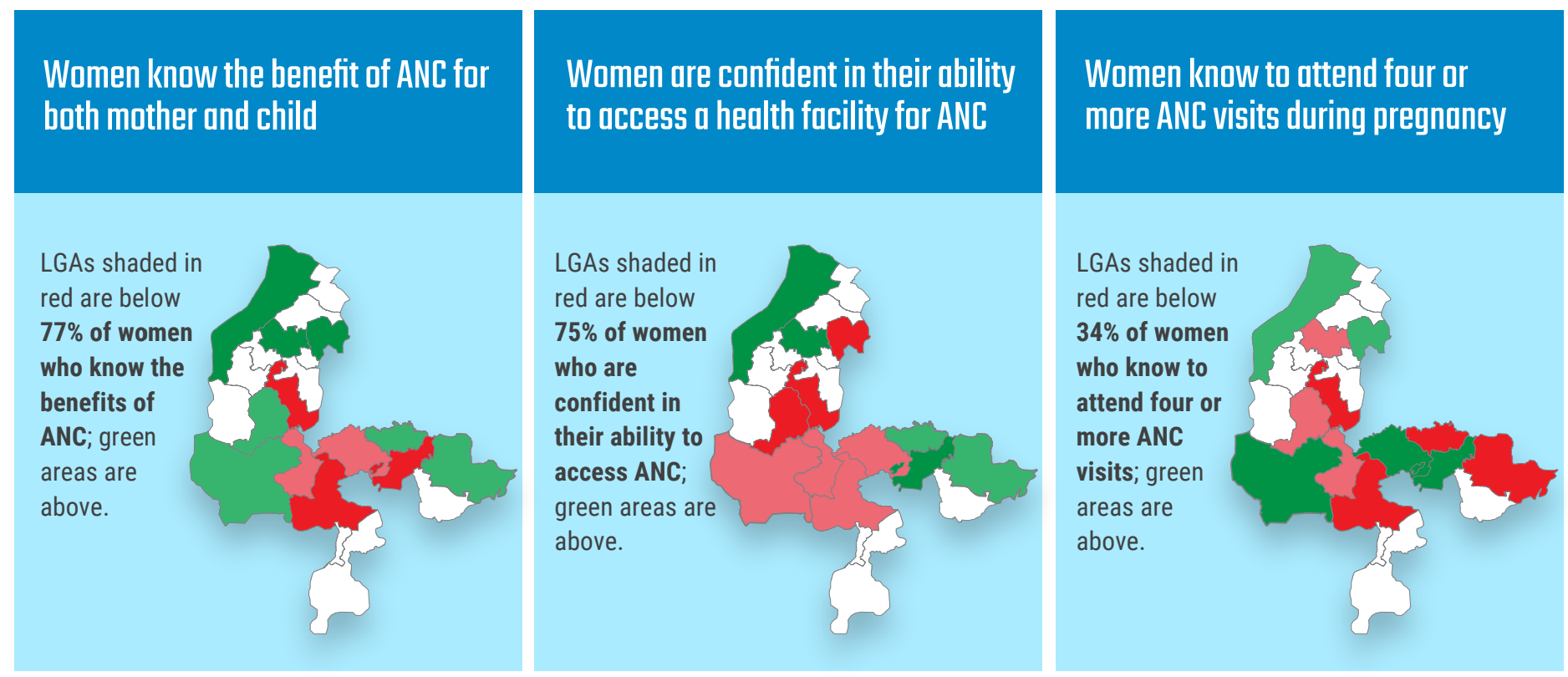

Notes: Lightly shaded areas are immediately below or above the median. Darker shaded areas are further away from the median, below the 25 th or above the 75th percentile. LGAs in white were not sampled for the survey and information is not available for these areas.

\section{How can this information be used to improve the use of ANC services in Kebbi State?}

Discussion and inquiry into ANC barriers and facilitators may provide insights on how to enhance efforts in these areas by asking questions such as:

- What is different in LGAs with women who have less knowledge and confidence in seeking ANC services?

- What is different about the communities that may explain how well an LGA is doing? Do they have stronger leaders, ward development committees, or levels of community engagement in health issues?

- What is different about the households in the LGAs that may explain how well an LGA is doing? Are households closer to health facilities? Are households wealthier or more educated?
- What barriers are present in LGAs with lower knowledge and confidence in going to ANC services? How can these barriers be addressed by community leaders and members of the community?

- Do LGAs with higher levels of knowledge and confidence have facilitators that increase women's ability to go to ANC services? How can they be adopted in other areas with lower levels of ANC use?

- How can additional efforts be made or information tailored to reach communities and households in the greatest need of improving their knowledge and confidence in obtaining ANC services? 


\section{Increasing Use of Antenatal Care Services Among Women in Kebbi State}

The Breakthrough RESEARCH project conducted a behavioral surveillance survey for health among women who had a pregnancy or birth in the previous two years.

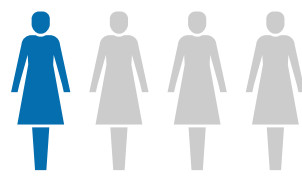

Fewer than 1 in 4 women $(\mathbf{2 4 \% )}$ in Kebbi State attended the recommended minimum of four antenatal care visits (ANC4+) during their last pregnancy.

\section{Survey Findings for Kebbi State}

The behavioral surveillance survey identified three important factors for improving women's attendance of ANC4+ during pregnancy. The percentages shown below are the averages for all of the LGAs sampled. These averages may differ from the median values shown on the previous page.
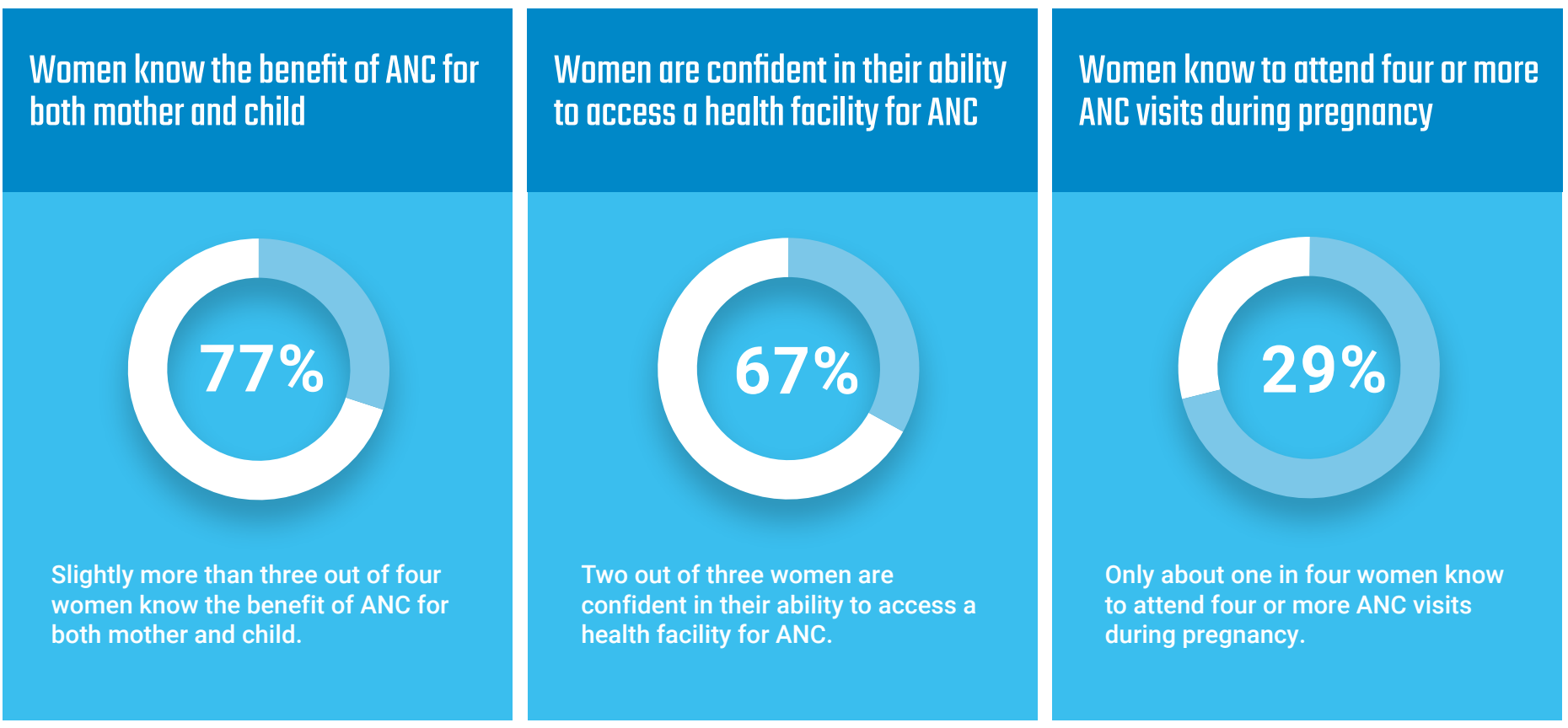

If these factors improved further, ANC4+ may rise in Kebbi State.

\section{Survey Results by Local Government Areas in Kebbi State}

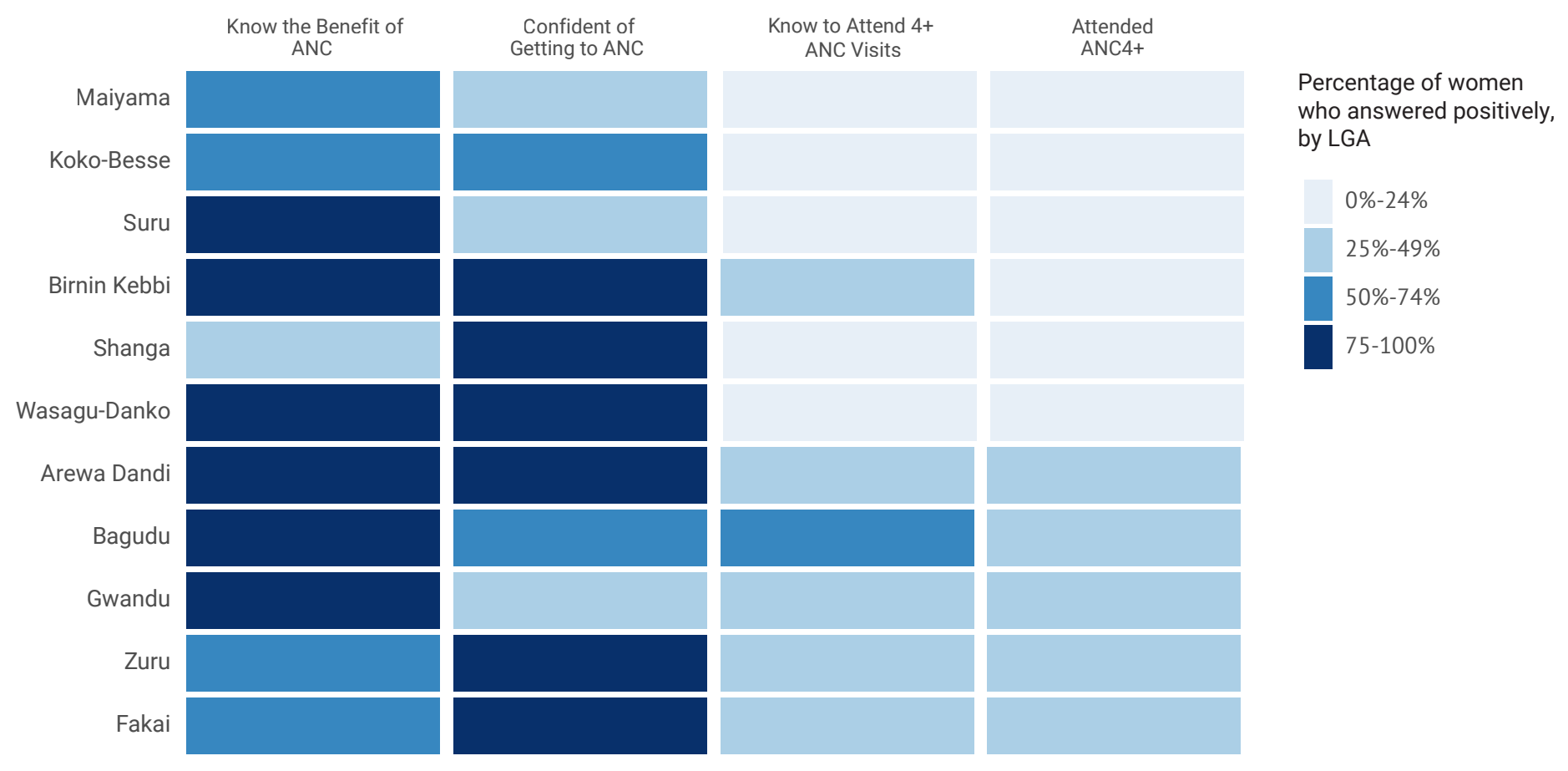

